\title{
PROLONGACIONES A PARTIR DE LAUDAN
}

Juan Igartua Salaverría

Universidad del País Vasco

\begin{abstract}
RESumen. La asimilación de la "duda razonable” al proceso penal español como estándar de prueba reporta grandes beneficios además de que encuentra un acomodo más garantista del que tiene en su ambiente jurídico originario, en los sistemas de common law. Esto, debido a la obligación de jueces y jurados de motivar en la sentencia o el veredicto ese particular aspecto. Con ello, por un lado se legitima la decisión jurisdiccional en la medida en que sólo una duda bien razonada acredita ser una "duda razonable”. Por otro, porque sólo cabe el control (procesal y extraprocesal) de lo público o de lo publicado, no de lo que se enclaustra en el recinto mental del juzgador.
\end{abstract}

\begin{abstract}
Assimilating "reasonable doubt" into the Spanish criminal procedure as a standard of proof is highly beneficial and, in addition, it finds a support which is more respectful with due process requirements than that which it is in its original legal scope, commonlaw systems. This is so, as a result of the judges' and juries' obligation to justify this specific aspect in their opinions or verdicts. By doing so, on the one hand, the court decision is legitimized in the sense that only a well reasoned doubt is recognized as a "reasonable doubt". On the other hand, control (procedural and extra-procedural) is only possible in the case of what is public or what has been published, and not in the case of what remains within the minds of those who judge.
\end{abstract}




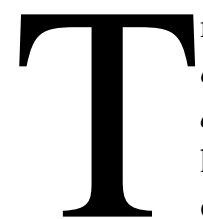

ras una morosa degustación del texto que el prof. Laudan (Por qué un estándar de prueba subjetivo y ambiguo no es un estándar) nos brinda, de buena gana yo declinaría la invitación de hilvanar algún comentario a su propósito por el simple motivo de que no sabría decir algo rentable. No obstante, me tomo la libertad de formular un puñado de apostillas sólo abocetadas, más con ocasión de lo dicho por Laudan que directamente sobre lo defendido por él.

1. La preocupación que copa el entero escrito de Laudan estriba en el tipo de instrucciones que se imparten a los jurados estadounidenses acerca del "estándar de prueba” (o quantum de prueba, como se estila decir aquí) requerido para emitir un veredicto de culpabilidad. Y, como subraya el autor, las formulaciones de curso más usual (tanto las de cuño cuantitativo como las cualitativas) tienen el común denominador de identificar finalmente el "estándar de prueba” con instancia tan subjetiva como resulta ser la convicción individual de cada jurado. Lo cual resulta catastrófico. (Si se desea conocer al detalle la ristra de contraindicaciones que eso comporta, léase también la impecable e implacable crítica de Jordi Ferrer a la "convicción” como actitud proposicional del juzgador ${ }^{1}$ ).

Yo me pregunto si el riesgo de semejante subjetivismo sólo acecha a los jurados y no así a los jueces profesionales de los Estados Unidos. Según mi información, la mayor parte de los procesos penales corren de la íntegra cuenta de jueces profesionales ya que la participación o no de los jurados es potestativa de los justiciables y éstos, por razones que no vienen ahora al caso, suelen optar con preferencia por jueces exclusivamente. ¿Qué pasa con los jueces? ¿Funcionan, de hecho, conforme a criterios más objetivos que los jurados por mucho que no acierten a explicárselos cuando los instruyen? ¿O las fórmulas que emplean en la instrucción de los jurados reflejan cabalmente su propia práctica? Se trata seguramente de preguntas retóricas, así que las dejo estar.

2. Dice Larry Laudan que su análisis se ciñe al derecho anglosajón y, por razones biográficas, también al mejicano; y que, si bien no está dispuesto a afirmar que su crítica se aplica por doquier, sin embargo aventura la suposición de que lo dicho vale parecidamente para la mayor parte de los sistemas europeos de justicia penal. Pues bien, el manojo de comentarios que seguirá a continuación provienen de mi inevitable instalación en un sistema jurídico singular (no sólo por ser uno sino, además, por algunos rasgos distintivos

${ }^{1}$ En su libro Prueba y verdad en el derecho, Madrid-Barcelona, $2^{\text {a }}$ ed., 2005; pp. 80-96. 
de nuestro jurado ${ }^{2}$; institución ésta -la del jurado- protagonista en exclusiva del paper de Laudan, aunque eso tendrá sólo relativa importancia en lo que sigue).

Por mucho que yo siga un periplo más bien casual, anticiparé que el propósito que recorre esta mi gavilla de comentarios consiste en mostrar el beneficio que puede reportar al proceso penal español la asimilación de la “duda razonable” como estándar de prueba y cómo éste puede hallar en nuestro derecho procesal acomodo más garantista del que encuentra en su propia cuna, es decir en los sistemas de common-law.

3. En lo que toca a España, me temo que las cosas están aún más verdes que en los Estados Unidos; pues entre nosotros, amén de concebir también la “convicción” y la “duda” en clave meramente psicológica, por añadidura se ha generado -según subraya Perfecto Andrés ${ }^{3}$ - una confesada resistencia a incluir el "in dubio pro reo" en esa constelación de elementos que se suele articular en derredor de la presunción de inocencia ${ }^{4}$, es decir una aversión a conceder que la presunción de inocencia reporta un más exigente estándar de prueba. No se me escapa -como ha observado Taruffo ${ }^{5}$ - que la presunción de inocencia no implica per se un nivel de prueba particularmente elevado bastando con una probabilidad prevalente a favor del enunciado acusatorio; si bien -apunta ese mismo autor- hay poderosas razones de naturaleza ético-política e incluso jurídica para prescribir un estándar probatorio destacadamente alto en el proceso penal. De todos modos, no va por esos derroteros analítico-conceptuales (es decir si hay o no implicación lógica entre la presunción de inocencia y un específico quantum de prueba) la renuencia de significados sectores españoles (de la jurisdicción y de la doctrina) a incardinar el "in dubio" dentro de la presunción de inocencia; importa señalar -por lo que atañe en perpendicular al texto de Laudan- que esa postura reactiva española obedece justamente a una oposición a traducir el "in dubio pro reo" en un estándar de prueba controlable y, por eso, al menos medianamente objetivo ${ }^{6}$.

\footnotetext{
${ }^{2}$ Me refiero a la circunstancia de que aun siendo el jurado español de corte "puro o anglosajón”, a diferencia de éste tiene la obligación de motivar su veredicto.

3 “Sobre prueba y proceso penal”, Discusiones, 2003, n 3; p. 62.

${ }^{4}$ A los que se dedica un cuidadoso análisis en el reciente libro de M. Fernández López, Prueba y presunción de inocencia, Madrid, 2005.

5 “Conocimiento científico y estándares de prueba judicial”, Jueces para la Democracia, 2005, n 52; p. 71.

${ }^{6}$ Semejante argumentación se dejaría sintetizar de este modo: 1)la presunción de inocencia, siendo como es un derecho fundamental, puede servir para fundamentar un recurso de casación (ante el TS) y de amparo (ante el TC); 2) ahora bien, como la convicción de los tribunales de instancia no es revisable ni en casación ni en amparo, el control sobre la observancia de la presunción de inocencia se refiere a facetas distintas de la valoración de las pruebas; 3) y como
} 
Es cierto que, en medio de ambiente tan adverso, algunos han acometido la supuesta gesta de reintroducir la regla del "in dubio pro reo” en el corazón de la presunción de inocencia, pero de una manera bastante peculiar. ¿Y qué se ha ganado con ello? Absolutamente nada. Veamos, si no, lo que escribe un notísimo penalista y magistrado del TS (y, al parecer, engolosinado por la producción doctrinal alemana). Dice: “el principio in dubio pro reo tiene dos dimensiones que se deberían distinguir: una dimensión normativa y una dimensión fáctica que, en general, no han sido tenidas en cuenta por la jurisprudencia ni por la doctrina. En esta última -la dimensión fáctica- el principio hace referencia al estado individual de duda de los jueces, y por lo tanto debe quedar fuera de la casación, pues el Tribunal de casación no puede obligar al Tribunal a quo a dudar cuando éste está realmente convencido respecto del sentido de una prueba que se ha percibido directamente. Por el contrario, la dimensión normativa se manifiesta en la existencia de una norma que impone a los jueces la obligación de absolver cuando no se hayan podido convencer de la culpabilidad del acusado. Esta norma es vulnerada cuando se condena sin haber alcanzado tal convicción””. O sea, lo determinante del "in dubio" consiste en comprobar si el juez ha sido consecuente (absolviendo si previamente ha manifestado tener alguna duda o condenando si ha expresado no tenerla), pero estaría vedado inquirir sobre el fundamento de la convicción o de la duda ${ }^{8}$. Por tanto, la dimensión normativa del "in dubio" (la única que de verdad contaría) queda a expensas de cualquier accidental e incontrolada convicción del juzgador. ¿Y para semejante nadería vale la pena esforzarse por la inclusión del "in dubio pro reo” en el cogollo de la presunción de inocencia?

Repárese, encima, que en ese planteamiento no hay siquiera conciencia de la naturaleza problemática de nociones tales como "convicción” o “duda”. Aquí se está lejísimos de los variados intentos -por fallidos que a la postre hayan resultado- que afloran en múltiples sentencias de tribunales norteamericanos y de los que Larry Laudan ha dado cuenta crítica en otro

\footnotetext{
la regla del "in dubio pro reo" se enclava en el centro mismo de la valoración de las pruebas, aquélla es ajena al principio de la presunción de inocencia.

${ }^{7}$ E. Bacigalupo Zapater, "La impugnación de los hechos probados en el recurso de casación penal”, Estudios de Jurisprudencia, 1992, n ${ }^{\text {1; p. }} 53$.

${ }^{8}$ Ese planteamiento me parece, con todos los respetos, no menos inatendible que, si ante un ciudadano que se cree Napoleón, omitimos inquirir en qué se cimenta esa creencia y ceñimos nuestra atención a observar si el citado sujeto adopta la pose que se atribuye al emperador francés (el brazo derecho cruzado sobre el pecho y la mano introducida en la casaca). Y si no lo hace, se le toma por loco; no por creerse Napoleón (cada cual es libre de creerse lo que quiera, como el juez es libre al valorar las pruebas) sino por no adecuar el gesto al personaje.
} 
trabajo suyo 9 . Me refiero a los ensayos por definir la regla de "más allá de la duda razonable” en términos p.ej. de "seguridad apropiada para asumir decisiones importantes para la vida propia”, o a redefinir la "duda razonable” p.ej. como "la duda que induciría a una persona prudente a dudar de si hacer algo o no”, y así sucesivamente. Tanteos -como dije- tal vez saldados con el fracaso pero que, cuando menos, dejan traslucir las inquietudes de una jurisprudencia (la norteamericana) traspasada de honestas vacilaciones a la hora de formular el significado de "convicción” y de “duda razonable”. En cambio, nada de parecidas inquietudes garantistas en la susodicha y satisfecha élite española que dice frecuentar "la doctrina europea actual" o "la moderna doctrina procesal” (cuyo mentor, no sé si más relevante o simplemente compendioso, parece ser Claus Roxin ${ }^{10}$.

4. Ignoro si la mentada avanzadilla española ha sucumbido ante el prejuicio de "quod non est in Germania non est in Europa", pero lo cierto es que ya algunos prominentes tribunales italianos (el de Casación entre ellos) -influidos seguramente por el libro Giustizia e modernità de Federico Stella ${ }^{11}$ - se apartan de la idea (de Roxin, entre otros) según la cual "el principio del in dubio no es una regla de valoración de la prueba, sino que entra en funcionamiento sólo después de que la valoración de la prueba haya concluído”12, y en su lugar proclaman que “el más allá de la duda razonable” debe constituir "la regla probatoria y de juicio en el proceso penal, indispensable para asegurar la protección de los inocentes y el respeto de los fundamentos constitucionales del Estado"13. Pues bien, lamentablemente no ha llegado noticia de semejante viraje a personas que presumen de estar al corriente de "la doctrina europea actual”, como si eso de la "duda razonable” fuera una pieza procesal de la "cultura jurídica anglosajona” que a nosotros no nos afecta ${ }^{14}$.

9 “Is 'Reasonable Doubt' Reasonable?”, Legal Theory, 2003, n 3.

${ }^{10}$ E. Bacigalupo Zapater, "Doble instancia y principio de inmediación (A propósito de la llamada “doble instancia”), Actualidad Penal, 2002, n 12; p. 289 nota 33.

${ }^{11}$ La referencia completa es Giustizia e modernità. La protezione dell'inocente e la tutela delle vittime, Milán, 2001.

${ }^{12}$ C. Roxin, Strafverfahrensrecht, 25 ed., Munich, 1998; p. 106.

${ }^{13}$ Citado en F. Centonze, "La Corte d'assise di fronte al 'ragionevole dubbio'”, Rivista italiana di diritto e procedura penale, 2003, núms. 1-2; pp. 673-674. En esta misma revista aparecen otras dos contribuciones que abundan en la incidencia de la regla del "más allá de la duda razonable” en la jurisprudencia de la Corte di cassazione, a saber: G. CANZIO, "L' 'oltre il ragionevole dubbio' como regola probatoria e di giudizio nel processo penale”, 2004, n 1; y F. D'Alessandro, "L'oltre ogni ragionevole dubbio nella revisione del processo”, 2004, n 2.

14 "La presunción de inocencia, a diferencia de como es entendido este derecho en la cultura jurídica anglosajona, no requiere que el Juzgador llegue a un estado de convicción que 
Por contra, otros que en España también otean -pero sin tanta fanfarria- horizontes internacionales, sí han tenido ocasión de sintonizar con esa onda ${ }^{15}$. Y entre unos (los italianos) y otros (algunos españoles contados) nos han abastecido de enseñanzas para captar el meollo del problema que afronta Laudan: el de conferir objetividad y operatividad garantista a la regla del “más allá de la duda razonable” en tanto que estándar probatorio.

5. Nada tengo que oponer a la justificada severidad con que Laudan denuncia el subjetivismo en el que se disuelven las más socorridas formulaciones que pretenden concretar el nivel de prueba exigible para emitir un veredicto (o una sentencia, en su caso) de culpabilidad. Ni me toca nada que añadir a su certero y didáctico análisis acerca del contrasentido que encierra el valorar las propias creencias en términos de probabilidad cuantitativa. Ni menos osaría discutir la conveniencia de que aquél listado de fórmulas subjetivistas haya de ser reemplazado por un criterio de corte objetivo tal como que se debe considerar superado el listón de la "duda razonable” cuando, a la vista de los elementos de prueba acreditados, no es posible sostener una hipótesis mínimamente creíble alternativa a la de la acusación.

No obstante, de esto último deseo decir alguna cosa. De poco valdría haber conquistado un criterio objetivo si, luego, no lo blindamos para evitar una recaida en la subjetividad. Obviamente -como sostiene Laudan- es necesario formular correctamente el estándar probatorio del "más allá de la duda razonable”, pero quizás eso no sea suficiente. Pues, además: primero se precisa entenderlo rectamente; luego aplicarlo adecuadamente; y, finalmente, como corresponde a un estándar que se precie de objetivo, hay que arbitrar algún mecanismo para controlar si ha sido manejado o no como es debido por el órgano judicial de turno. Vayamos por partes.

6. En principio, la correcta formulación lingüística de un estándar probatorio no asegura el que todos lo vayan a entender de la misma manera; particularmente que todos tengan conciencia precisa de cuáles son las concretas implicaciones del susodicho estándar. Pues, por ejemplo, cifrar el nivel de la "duda razonable” en la "credibilidad” (mínimamente plausible) que merece la hipótesis que beneficia al acusado, no cierra de por sí la puerta al descontrol de la subjetividad (por la sencilla razón de que la atribución

despeje toda duda razonable acerca de la culpabilidad del acusado” (J. A. Choclán Montalvo, "El derecho constitucional a la presunción de inocencia”, VV. AA., Derechos procesales fundamentales, Madrid, 2005; p. 648).

${ }^{15}$ Pongo como ejemplo, dentro de una nómina bastante breve, al magistrado J.M. De Paul Velasco, "Presunción de inocencia e in dubio pro reo en el juicio ante el Tribunal de Jurado", en VV.AA., La Ley del Jurado: problemas de aplicación práctica, Madrid, 2004. 
de “credibilidad” está no pocas veces a expensas de los prejuicios de cada cual). Por eso, es imprescindible que los juzgadores (jurados o jueces) dispongan de un suplemento informativo para objetivar (en lo que quepa) el modus operandi conducente a decantarse a favor o en contra de reconocer la plausibilidad o credibilidad de una determinada hipótesis.

Para no andarme por las ramas, me valdré de una ilustración extraida de la jurisprudencia del TC (que es un saco de contradicciones). El TC, a pesar de su expreso rechazo -como antes apunté- a incluir el "in dubio" en el equipaje de la presunción de inocencia, en la práctica termina por aceptarlo. Pero lo hace de manera equivocada. Eso ocurre p.ej. en la STC 137/2002 donde se recuerda la doctrina de que la presunción de inocencia no se destruye con "inferencias no concluyentes por excesivamente abiertas, débiles o indeterminadas” (FJ 7). No está mal la idea. Pero, sorpresivamente, eso no impide que el TC -p.ej. en la STC 135/2003- advierta que "constituye doctrina consolidada de este Tribunal que no nos (...)es posible que entremos en el análisis de otras posibles inferencias distintas a las efectuadas por los órganos judiciales”. Entonces, ¿cómo se las arregla el TC para concluir que la inferencia realizada por el tribunal $a$ quo "ha de reputarse excesivamente abierta”? ¿cómo se determina si una inferencia es o no “abierta”, “débil” o "indeterminada" (suponiendo que sea correcto hablar en esos términos)? ¿acaso guiándose por la impresión subjetiva de cada cual o, más bien, examinando si caben otras inferencias (empezando por la que propone la defensa)? Y conste que esto sería sólo el punto de partida de un recorrido epistemológicamente correcto, del que omitiré ocuparme porque ya ha sido explorado con detalle entre nosotros por Marina Gascón ${ }^{16}$ o por Daniel González-Lagier ${ }^{17}$.

7. Hay más todavía. Aun concordando en que la credibilidad de una determinada hipótesis es relativa, o sea depende de su comparación con otras hipótesis rivales, surge un nuevo problema: ¿y cómo se aplica ese cotejo? Esta pregunta necesita una explicación, a la vista de al menos uno (no el único, claro) de los plurales problemas a que da lugar.

Si aceptamos (y Laudan parece de la opinión) que la "verdad” (al menos como ideal regulativo) es un objetivo central del proceso ${ }^{18}$, habremos de

\footnotetext{
${ }^{16}$ En su libro Los hechos en el derecho. Bases argumentales de la prueba, Madrid-Barcelona, 1999; esp. pp. 194-228 (hay una segunda edición del año 2004).

${ }^{17}$ En el amplio estudio, dividido en dos partes, "Hechos y argumentos (Racionalidad epistemológica y prueba de los hechos en el proceso penal)” (I y II), Jueces para la Democracia, 2003; núms. 46 y 47 respectivamente.

${ }^{18}$ Permítaseme un breve inciso acerca de si y de qué modo se incluye la "verdad" entre las finalidades del proceso penal. No parece que las dos implicaciones de la presunción de inocen-
} 
suponer que la relación de hechos probados que contiene una sentencia (e incluso un veredicto del jurado, en España) implica una relación de correspondencia entre una entidad lingüística (el “enunciado” que verbaliza la reconstrucción histórica de un hecho) y una entidad extralingüística (el "hecho” real, objeto del juicio). Pero esta línea referencial que debiera enlazar ambas entidades, se convierte en el proceso (como en cualquier reconstrucción histórica) en una línea inferencial (puesto que el referente es un hecho del pasado y ya no lo tenemos ante los ojos) ${ }^{19}$.

Normalmente, la reconstrucción del "hecho” (objeto de la causa) está trufada de varias y variadas inferencias que afectan tanto a la fiabilidad que merece cada medio de prueba como al trayecto que conduce desde los medios de prueba al factum probandum. Pues bien, la inferencia que concierne a la fiabilidad atribuída a cada medio de prueba debe insertarse en el conjunto de las inferencias que atañen a la fiabilidad asignada a los otros medios de prueba. Y, a su vez, la inferencia que conduce desde un medio de prueba, declarado atendible, al hecho a probar debe colocarse en una trama con las otras inferencias que ponen en relación los otros medios de prueba, también atendibles, con el hecho de la causa.

¿Que a qué viene semejante banalidad? A poner al descubierto una "típica técnica de neutralización de las pruebas”20, que consiste en atomizar

cia como "regla de juicio” (a saber: el desequilibrio de la carga de la prueba entre las partes -a favor del imputado- y el que esa carga deba alcanzar un nivel particularmente exigente) obedezcan a requisitos epistemológicos. Ahora bien, ¿significa eso que la "verdad sobre los hechos" carece de relevancia en el proceso penal? Dado que la "verdad sobre los hechos" es una expresión muy ambigua, conviene formular la cuestión atendiendo a qué se debe probar en el proceso penal. En éste no se busca reconstruir lo que pasó barajando indistintamente las hipótesis que fuera menester (p.ej. "Juan mató a Pedro” y su opuesta “Juan no mató a Pedro”), sino una sola, la acusatoria (es decir que “Juan mató a Pedro”), no así la exculpatoria; y, además, se exige que la hipótesis acusatoria esté refrendada por un elevado grado de probabilidad. ¿Quién negará protagonismo estelar al criterio de "verdad” el cometido de establecer el grado de probabilidad que asiste a la única hipótesis en juego? Conviene recordar que si la hipótesis incriminatoria no prospera en esas condiciones, de ahí no se sigue que deba entenderse como probada la hipótesis exculpatoria. Por tanto, absolver a un imputado (aunque realmente fuera culpable) porque los elementos de prueba disponibles no dotan a la hipótesis acusatoria de la probabilidad requerida no es un error.

Obviamente' los espacios dentro de los que rige el valor de la "verdad" pueden estar delimitados conforme a otros valores. Pero eso no nos coge de nuevas ni es idiosincrático del proceso penal, pues algo similar ocurre también en otro tipo de procesos en los que la ley (y no los criterios de verdad) determina algunos hechos que no necesitan prueba (p.ej. las presunciones) o excluye pruebas (por la prevalencia de otros valores sobre el valor de la "verdad") que potencialmente son aptas para el esclarecimiento de los hechos.

${ }^{19}$ P. Ferrua, "Processo penale e verità. Note in margine alla riforma del giusto processo", en S. Anastasia-M. Palma, La bilancia e la misura, Milán, 2000; p. 209.

${ }^{20}$ F. M. Iacoviello, La motivazione della sentenza penale e il suo controllo in Cassazione, Milán, 1997; p. 213. 
el examen de cada una de las inferencias, desarticulándola del contexto, y planteando la cuestión de la "duda razonable” a ese nivel. De ese modo, no es raro que frente a una inferencia, tomada aisladamente, quepa oponer otra no desprovista totalmente de fundamento; lo cual acarrea una exacerbación de la duda sobre cualquier certeza razonable.

Precisamente se nos brinda una muestra de tal proceder en un voto particular formulado por el antes mencionado Magistrado del TS, don Enrique Bacigalupo, que se oponía a que la certeza o la duda de un tribunal de instancia (en cuanto elemento "fáctico” y no "normativo”) fueran objeto de fiscalización. Pues bien, en el sonado caso Marey, enjuiciado directamente en primera y única instancia por el TS (debido al aforamiento de uno de los imputados), el Tribunal, por mayoría de 7 frente a 4, condenó a todos los acusados; entre ellos a quienes en la época de los hechos fueran, respectivamente, Ministro del Interior (José Barrionuevo) y Secretario para la Seguridad del Estado (Rafael Vera). Respecto de la culpabilidad de estos dos últimos, el Magistrado aludido suscitó en su voto particular la cuestión del "in dubio pro reo", pero no para disentir de la mayoría por una supuesta incongruencia de condenar pese a las dudas (cosa esperable si, conociendo la ya expuesta postura doctrinal de aquél, el TS actuara como tribunal de casación) sino -esta vez al funcionar el TS como tribunal de instancia- por no haber dudado cuando había razones para dudar. ¿Estamos, acaso, ante una briosa reivindicación de la “duda razonable”? Creo que no. El citado Magistrado, a lo largo de su voto particular, iba replicando a las sucesivas inferencias de la mayoría (de las que no puedo dar cuenta en esta intervención ${ }^{21}$ ) con una batería de "no es imposible”, “era perfectamente posible”... para rematar su argumentación (en la que se observa el sintomático y abusivo trueque de "posible” o "no imposible” por la expresión "igualmente plausible”) con las siguientes palabras: "El análisis realizado demuestra que los indicios de los que ha partido la mayoría de la Sala para dar credibilidad a las declaraciones de los coimputados que acusan a los señores Barrionuevo y Vera son, individualmente considerados ambiguos, es decir no excluyen otras hipótesis fácticas igualmente plausibles”. Pero, tras esa consideración individualizada (de por sí legítima), el Magistrado soslaya -¿por qué será?- cualquier intento de tejer, con un material hipotético de ya reducida plausibilidad, un relato fáctico o una "historia” disyuntiva dotada de una mínima coherencia.

En suma, ese voto particular ilustra a la perfección de qué manera un análisis atomizado de cada inferencia termina por desvitalizar el rendimien-

${ }^{21}$ Pero, por si alguien está interesado en ello, incurro en la inmodestia de remitirle a mi librito El caso Marey. Presunción de inocencia y votos particulares, Madrid, 1999. 
to de la actividad probatoria y desencadena una tumoral expansión de la “duda”. Por supuesto, nada más ajeno a la razonabilidad de la duda.

8. Pero ¿de qué aprovecha al acusado tanto énfasis en el recto entendimiento judicial de la "duda razonable” y en su correcta aplicación si, luego, todo ello se sustrae al control? ¿de qué vale velar por la objetividad de un estándar probatorio vinculante si, a la postre, no hay manera de objetivar su observancia? Si los estándares están para ser cumplidos, un estándar -como señala Perefecto Andrés citando a Binder- “está garantizado sólo cuando su incumplimiento genera la invalidez del acto que lo ha violado"22. ¿Y cómo se verifica que al juez o al jurado no se le ha desgobernado el manejo del estándar del “más allá de la duda razonable”? Imponiendo al juez o al jurado la obligación de motivar, en la sentencia o el veredicto, ese particular aspecto. Por un lado, porque así se legitima la decisión jurisdiccional, en la medida en que sólo una duda bien razonada acredita ser una "duda razonable”. Por otro, porque sólo cabe el control (procesal y extraprocesal) de lo público o de lo publicado, no de lo que se enclaustra en el recinto mental del juzgador.

Por eso apunté al comienzo que el susodicho estándar de la "duda razonable” estaría mejor garantizado en un sistema como el nuestro (en el que hasta el veredicto del jurado debe ser motivado) que en su ambiente jurídico originario (donde vige el veredicto inmotivado y la obligación de motivación de las sentencias carece de refrendo normativo-legal y hasta consuetudinario, según creo).

${ }^{22}$ P. Andres Ibañez, “Garantismo: una teoría crítica de la jurisdicción”, en M. Carbonell-P. Salazar (eds.), Garantismo. Estudios sobre el pensamiento jurídico de Luigi Ferrajoli, Madrid, 2005; p. 71.

\section{DOXA 28 (2005)}

